\title{
DAMPAK PROGRAM PUAP TERHADAP PENDAPATAN PETANI JAGUNG MARERIS DI DESA KAWANGKOAN KECAMATAN KALAWAT
}

\author{
Imanuel Sugandi Rompas \\ Joachim N. K. Dumais \\ Celcius Talumingan
}

\begin{abstract}
The purpose of this study was to compare the income of Mareris corn farmers before and after receiving the PUAP program in Kawangkoan Village, Subdistrict Kalawat, North Minahasa Regency. The benefit of this research is as a reference material to increase the income of farmer's corn.This research takes 3 (three) months starting from June 2016 in Kawangkoan Village, Kalawat Subdistrict. Method of data retrieval used in this research is primary data and secondary data. The primary data were obtained from interviews of farmers belonging to Marerist group. Secondary data is supporting data obtained from agricultural extension officer. Sampling is done by using the quota of 15 peasants. The results showed that at a confidence level $\alpha=5 \%, t_{\text {count }}=7.628>t_{\text {table }}=2.145$ so $H_{0}$ was rejected and $H_{1}$ accepted. Thus there are differences in income of corn farmers before and after receiving PUAP the program.
\end{abstract}

Keywords: Compare Income, PUAP Program, Kawangkoan Village, Subdistrict Kalawat

\begin{abstract}
ABSTRAK
Tujuan penelitian ini adalah membandingkan pendapatan petani jagung Mareris sebelum dan sesudah menerima program Pengembangan Usaha Agribisnis Perdesaan (PUAP) di Desa Kawangkoan, Kecamatan Kalawat. Manfaat penelitian ini adalah sebagai bahan referensi untuk meningkatkan pendapatan petani jagung. Penelitan ini berlangsung 3 (tiga) bulan dimulai dari bulan Juni 2016. Metode pengambilan data yang digunakan dalam penelitian ini adalah data primer dan data sekunder. Data primer diperoleh dari hasil wawancara petani anggota kelompoktani Mareris. Data sekunder merupakan data pendukung diperoleh dari penyuluh Dinas Pertanian. Pengambilan sampel dilakukan dengan menggunakan kuota sebanyak 15 orang petani. Hasil penelitian menunjukkan bahwa pada tingkat kepercayaan $\alpha=5 \%, \mathrm{t}_{\text {hitung }}=7,628>\mathrm{t}_{\text {tabel }}=2,145$ sehingga $\mathrm{H}_{0}$ ditolak dan $\mathrm{H}_{1}$ diterima. Dengan demikian terdapat perbedaan pendapatan petani jagung sebelum dan sesudah menerima program PUAP.
\end{abstract}

Kata kunci: Perbandingan pendapatan, program PUAP, Desa Kawangkoan, Kecamatan Kalawat. 


\section{PENDAHULUAN}

\section{Latar Belakang}

Desa Kawangkoan Kecamatan Kalawat merupakan daerah yang mendapat bantuan permodalan usaha agribisnis, di Desa Kawangkoan Kecamatan Kalawat dengan dana dari program Pengembangan Usaha Agribisnis Perdesaan (PUAP) yang dikelola oleh GAPOKTAN. GAPOKTAN tersebut adalah GAPOKTAN "Mareris" dana PUAP disalurkan pada bulan Oktober 2011 sebesar Rp. 100.000.000 ke 7 Kelompok Tani dan salah satu kelompok yang menerima bantuan dana PUAP adalah Kelompok Tani Mareris. Berdasarkan Data Statistik Desa Kawangkoan, tahun 2012 jumlah penduduk miskin tercatat 236 KK. Dari jumlah tersebut sekitar 1.222 jiwa berada dipedesaan dengan mata pencaharian utama disektor pertanian. Permasalahan mendasar yang dihadapi petani adalah kurangnya akses kepada sumber permodalan, pasar dan teknologi, serta organisasi tani yang masih lemah. Untuk itu penanggulangan kemiskinan merupakan bagian dari pelaksanaan rencana pembangunan jangka panjang dan kesepakatan global untuk mencapai tujuan pembangunan milenium. Kementerian Pertanian mulai tahun 2008 telah melaksanakan program PUAP dibawah koordinasi Program Nasional Pemberdayaan Masyarakat Mandiri (PNPM-Mandiri) dan berada dalam kelompok program pemberdayaan masyarakat.

Untuk koordinasi pelaksaan PUAP di Kementerian Pertanian, Menteri Pertanian membentuk Tim PUAP Pusat untuk mengkoordinasikan pelaksanaan PUAP Nasional. PUAP merupakan bentuk fasilitas bantuan modal usaha untuk petani anggota, baik petani pemilik, petani penggarap, buruh tani maupun rumah tangga tani yang dikoordinasikan oleh Gabungan Kelompok Tani (Gapoktan). Gabungan Kelompok Tani (Gapoktan) merupakan kelembagaan tani pelaksaan PUAP untuk penyaluran bantuan modal usaha bagi anggota. Untuk mencapai hasil yang maksimal dalam pelaksanaan
PUAP, Gapoktan di dampingi oleh tenaga Penyuluh Pendamping dan Penyelia Mitra Tani (PMT). Melalui pelaksanaan PUAP diharapkan Gapoktan dapat menjadi kelembagaan ekonomi yang dimiliki dan dikelola petani di Desa Kawangkoan. Gabungan Kelompok Tani (Gapoktan) merupakan kelembagaan tani pelaksaan PUAP untuk penyaluran bantuan modal usaha bagi anggota. Untuk mencapai hasil yang maksimal dalam pelaksanaan PUAP, Gapoktan di dampingi oleh tenaga penyuluh pendamping dan penyelia mitra tani (PMT). Melalui pelaksanaan PUAP diharapkan Gapoktan dapat menjadi kelembagaan ekonomi yang dimiliki dan dikelola petani di desa kawangkoan. Untuk mencapai tujuan PUAP, yaitu mengurangi tingkat kemiskinan dan pengangguran di perdesaan, PUAP dilaksanakan secara teritegrasi dengan kegiatan Kementerian Pertanian maupun Kementerian/Lembaga lain dibawah payung program PNPM.

\section{Perumusan Masalah}

Berdasarkan latar belakang diatas, maka peneliti merumuskan masalah sebagai berikut. Apakah ada dampak dari program PUAP terhadap peningkatan pendapatan petani jagung Mareris di Desa Kawangkoan Kecamatan Kalawat?

\section{Tujuan Penelitian}

Tujuan penelitian ini adalah membandingkan pendapatan petani jagung Mareris sebelum dan sesudah menerima program PUAP di Desa Kawangkoan Kecamatan Kalawat.

\section{Manfaat Penelitian}

Manfaat penelitian adalah sebagai bahan referensi untuk meningkatkan pendapatan petani. 


\section{METODOLOGI PENELITIAN}

\section{Waktu dan Tempat Penelitian}

Penelitian ini berlangsung selama 3 (tiga) bulan di mulai dari bulan Juni sampai Agustus 2016, dari persiapan hingga penyusunan laporan hasil penelitian. Penelitian dilakukan di Desa Kawangkoan Kecamatan Kalawat.

\section{Metode Pengumpulan Data}

Metode yang digunakan dalam penelitian ini adalah data primer dan data sekunder. Data primer adalah data yang diperoleh melalui wawancara yang dilakukan terhadap petani jagung. Data sekunder merupakan data pendukung diperoleh dari penyuluh Dinas Pertanian Kabupaten Minahasa Utara.

\section{Metode Pengambilan Sampel}

Penentuan lokasi penelitian dilakukan secara tunjuk sengaja (purposive sampling) yaitu Kelompoktani Mareris. Kemudian pengambilan sampel dilakukan dengan menggunakan kuota sebanyak 15 orang petani dari Kelompoktani Mareris.

\section{Konsepsi Variabel}

Adapun variabel-variabel yang akan diukur dalam penelitian ini adalah :

1. Karakteristik Responden, yaitu profil Kelompok Tani Mareris sebagai wadah yang menampung 15 responden sebagai anggotanya.

2. Luas lahan yaitu luas keseluruhan lahan yang digunakan dalam usahatani jagung (Ha).

3. Biaya produksi yaitu biaya yang dikeluarkan petani selama proses produksi jagung selama satu kali panen yang terdiri dari :

a. Biaya tetap :

- Pajak (Rp)

- Penyusutan alat bangunan (Rp)

b. Biaya variabel :

- Benih (Rp)

- Pupuk (Rp)

- Pestisida (Rp)

- Tenaga kerja (Rp)

- Sewa Pengangkutan (Rp)
4. Jumlah produksi yaitu jumlah produksi usahatani jagung $(\mathrm{Kg})$ dalam ukuran waktu selama satu kali panen.

5. Harga jual yaitu harga jagung yang berlaku di tingkat petani $(\mathrm{Rp} / \mathrm{Kg})$.

6. Penerimaan yaitu perkalian antara produksi dan harga jual untuk tanaman jagung selama satu kali panen (Rp).

7. Pendapatan yaitu selisih antara penerimaan dan biaya usahatani jagung ( $R p)$ selama satu kali panen.

\section{Metode Analisis Penelitian}

Data yang diperoleh dalam penelitian ini disajikan dalam bentuk tabel kemudian dianalisis secara deskriptif dan menggunakan rumus pendapatan petani.

Rumus Pendapatan Petani :

$$
\boldsymbol{\pi}=\boldsymbol{T R}-\boldsymbol{T C}
$$

Uji yang digunakan dalam penelitian ini adalah uji two sample assuming equal variancedimana uji digunakan untuk melihat atau mengetahui perbangdingan pendapatan usahatani jagung sebelum dan sesudah menerima bantuan program PUAP Gapoktan di Desa Kawangkoan Kecamatan Kalawat dengan bantuan alat analisis menggunakan SPSS dengan hipotesis :

$\mathrm{H}_{0}$ : Pendapatan petani sebelum menerima progam PUAP Gapoktan sama dengan pendapatan petani sesudah menerima program PUAP Gapoktan.

$\mathrm{H}_{1}$ : Pendapatan petani sebelum menerima program PUAP Gapoktan lebih besar dari pendapatan petani sesudah menerima program PUAP Gapoktan.

Dengan kriteria keputusan :

Jika $\mathrm{t}_{\text {hitung }}>\mathrm{t}_{\alpha(\mathrm{db})}=\mathrm{H}_{0}$ ditolak $; \mathrm{H}_{1}$ diterima

Jika $t_{\text {hitung }}<\mathrm{t}_{\alpha(\mathrm{db})}=\mathrm{H}_{0}$ diterima $; \mathrm{H}_{1}$ ditolak

\section{HASIL DAN PEMBAHASAN}

\section{Profil Kelompoktani Mareris}

Kelompok Tani Mareris didirikan pada tanggal 20 Januari tahun 2005 oleh hukum tua desa Kawangkoan kecamatan Kalawat kabupaten Minahasa Utara sesuai dengan SK Bupati Minahasa Utara Nomor 19a dengan 
ketua Bapak Jantje Suma. Awal mula berdiri kelompok tani ini beranggotakan 20 orang. Kelompok tani ini melakukan kegiatan usahatani jagung, palawija, dan kedelai. Selain itu, kelompok tani Mareris mengikuti beberapa kegiatan yang diselenggarakan oleh Pemerintah yaitu:

1. Diklat Agribisnis Tanaman Jagung Bagi Petani.

2. Pelatihan Penangkaran Benih Padi Kepada Petani di Kabupaten Minahasa Utara.

3. Workshop Action Research Facilities (ARF) Dalam Mendukung FMA di Kabupaten Minahasa Utara.

\section{Luas Lahan}

Luas lahan dalam penelitian ini yaitu luas keseluruhan lahan yang digunakan dalam kegiatan usahatani anggota kelompok tani mareris (responden).

Tabel 1. Luas Lahan (Ha)

\begin{tabular}{ccc}
\hline \multirow{2}{*}{ Responden } & \multicolumn{2}{c}{ Luas Lahan (Ha) } \\
\cline { 2 - 3 } & $\begin{array}{c}\text { Sebelum } \\
\text { PUAP }\end{array}$ & $\begin{array}{c}\text { Sesudah } \\
\text { PUAP }\end{array}$ \\
\hline 1 & 5 & 7 \\
2 & 1 & 2 \\
3 & 1 & 2 \\
4 & 1 & 4 \\
5 & 1 & 3 \\
6 & 1 & 2 \\
7 & 1 & 3 \\
8 & 2 & 4 \\
9 & 3 & 5 \\
10 & 1 & 2 \\
11 & 1 & 3 \\
12 & 1 & 4 \\
13 & 1 & 3 \\
14 & 1 & 2 \\
15 & 1 & 3 \\
\hline
\end{tabular}

Sumber: Diolah dari data primer (2016)

Tabel 1 menunjukkan luas lahan yang dimiliki sebelum menerima PUAP dan sesudah menerima PUAP. Seluruh responden mengalami perubahan luas lahannya setelah menerima PUAP. Lahan yang dimiliki oleh masing-masing responden merupakan lahan milik sendiri.

\section{Biaya Variabel \\ Biaya variabel adalah biaya yang} harus dikeluarkan seiring dengan bertambah atau berkurangnya produksi dan akan mengalami perubahan jika volume produksi berubah. Komponen biaya variabel dalam usahatani oleh masing-masing anggota Kelompok Tani Mareris (responden) meliputi Benih, Pupuk (UREA, SP36, KCl) Pestisida, Tenaga Kerja, dan Transportasi. Rincian biaya variabel sebelum PUAP dan sesudah PUAP.

1. Benih. Benih yang digunakan oleh masingmasing responden adalah jagung. Benih diperoleh dari toko PT. Pertani yang dijual seharga Rp. 32.000,00/kg. Masing-masing responden membeli dalam jumlah yang berbeda-beda sesuai dengan luas lahan yang dimiliki.

2. Pupuk dan Pestisida. Pupuk yang digunakan adalah pupuk UREA, SP36, $\mathrm{KCl}$ dan Pestisida diperoleh dari PT. Pertani dengan harga Rp. 1.500,00/kg (UREA), Rp. 2.100,00/kg (SP36), Rp. 2.500,00/kg (KCl), Rp. 65.000,00/liter (Pestisida). Pupuk dan pestisida dibeli oleh masing-masing responden sesuai dengan kebutuhan.

3. Tenaga Kerja. Upah dan jumlah tenaga kerja yang dimiliki oleh masing-masing responden berbeda-beda sesuai dengan jenis pekerjaan seperti pengolahan tanah, penanaman, pemupukan, penyiangan, pemberantasan hama dan penyakit, dan panen produk. Upah tenaga kerja dibidang pertanian adalah sebesar Rp. 100.000/HOK.

4. Transportasi. Transportasi yang digunakan untuk kegiatan pasca panen adalah mobil bak terbuka dengan biaya yang sama tiap responden yaitu Rp. 2.500.000,00. Selain itu dalam kegiatan pasca panen lainnya selain pengangkutan hasil produksi, tenaga kerja melakukan pembersihan dengan biaya Rp. 
500.000,00 sampai dengan Rp. 1.000.000,00., dan biaya penjemuran sebesar Rp. 1.000.000,00. Jika dilihat dari tabel biaya variabel yang terdapat dalam lampiran 4 pada halaman 26 dan lampiran 5 pada halaman 27 , dampak diberikannya PUAP terhadap masing-masing responden dalam kelompok tani Mareris sudah terlihat, yaitu meningkatnya biaya variabel dikarenakan biaya-biaya yang dibutuhkan selama kegiatan produksi lebih besar dari sebelumnya.

\section{Jumlah Produksi, Penerimaan, dan Pendapatan}

Jumlah produksi, penerimaan, dan pendapatan dalam usahatani oleh masingmasing responden dihitung berdasarkan waktu sekali panen yakni tiap $3-4$ bulan. jumlah tersebut dijelaskan dalam pada Tabel 2.

Tabel 2. Rata-rata Produksi, Penerimaan dan Pendapatan Sebelum dan Sesudah PUAP

\begin{tabular}{ccc}
\hline Uraian & \multicolumn{2}{c}{ Jumlah Rata-rata (Rp) } \\
\cline { 2 - 3 } & $\begin{array}{c}\text { Sebelum } \\
\text { PUAP }\end{array}$ & $\begin{array}{c}\text { Sesudah } \\
\text { PUAP }\end{array}$ \\
\hline $\begin{array}{c}\text { Produksi } \\
\text { (Rp) }\end{array}$ & $9.460 .599,8$ & $16.007 .200,07$ \\
$\begin{array}{c}\text { Penerimaan } \\
\text { (Rp) }\end{array}$ & $18.639 .666,67$ & $31.533 .333,33$ \\
$\begin{array}{c}\text { Pendapatan } \\
\text { (Rp) }\end{array}$ & $9.179 .066,867$ & $15.526 .133,27$ \\
\hline
\end{tabular}

Sumber: diolah dari data primer (2016)

Tabel 2 menunjukkan rata-rata perbandingan jumlah produksi, penerimaan, dan pendapatan dari usaha tani kelompok tani Mareris terjadi peningkatan. Dengan demikian dampak dari adanya pemberian PUAP terhadap kelompok tani mareris ini sangat membantu meningkatkan pendapatan.

\section{Hasil dan Pembahasa n}

Untuk menguji perbedaan pendapatan petani jagung desa Kawangkoan Kec. Kalawat sebelum dan sesudah menerima Program PUAP digunakan SPSS 20. Hasil penelitian menunjukkan bahwa ada tingkat kepercayaan pada $\alpha=5 \%, \mathrm{t}_{\text {hitung }}=7,628>\mathrm{t}_{\text {tabel }}=2,145$ sehingga $\mathrm{H}_{0}$ ditolak dan $\mathrm{H}_{1}$ diterima. Dengan demikian terdapat perbedaan pendapatan petani jagung sebelum dan sesudah menerima program PUAP.

\section{KESIMPULAN DAN SARAN}

\section{Kesimpulan}

Program Pengembangan Usaha Agribisnis Perdesaan (PUAP) memberikan dampak positif terhadap pendapatan petani jagung di Desa Kawangkoan Kecamatan Kalawat oleh adanya perbedaan antara pendapatan petani jagung yang signifikan antara sebelum dan sesudah menerima PUAP.

\section{Saran}

Kepada petani disarankan untuk menambah jumlah produksi jagung dan dapat mengalokasikan dana PUAP dengan sebaik mungkin untuk mempertahankan peningkatan pendapatan petani.

\section{DAFTAR PUSTAKA'}

Aulia, A, V., 2008. Analisis Pendapatan Usahatani Padi dan Kelayakan Usahatani Vanili Pada Ketinggian Lahan 350-800 M DPL di Kabupaten Tasikmalaya (Studi Kasus : Desa Cibongas, Kecamatan Pancatengah, Kabupaten Tasikmalaya). Program Studi Ekonomi Pertanian dan Sumberdaya Fakultas Pertanian. Institusu Pertanian Bogor. Bogor.

Asnida, M., 2015. Evaluasi Dampak Kebijakan Pemberdayaan Petani Melalui Program Bantuan Langsung Masyarakat Pengembangan Usaha Agribisnis Perdesaan (BLM-PUAP) di Kabupaten Pesawaran (Studi Kasus Desa Taman Sari Kecamatan Gedong Tataan). Program Studi Ilmu Administrasi Negara. Universitas Lampung. Lampung. Diakses pada

http://repository.ipb.ac.id/handle/1234567 89/1371.29 Mei 2015. 
Ayu, G dan Agustyari, K., 2013. Perbandingan Pendapatan Usahatani Jagung Manis danPadi di Subak Delod Sema Padanggalak Desa Kesiman Petilan Kecamatan Denpasar Timur (Jurnal). Program Studi Agribisnis Jurusan Pertanian. Universitas Udayana. Denpasar. Vol 2, No 4, Oktober 2013. Diakses pada http://psp.pertanian.go.id/ assets/file/2014/juknis\%20 pendamping pdf 202014. Hari Jumat, 29 Mei 2015.

Fatma, P., 2012. Artikel Evalusi Program Pengembangan Usaha Agribisnis Perdesaan di Kabupaten Solok. Program Studi Perencanaan Pembangunan. Universitas Andalas Padang. Padang.

Hanafie, R., 2010. Pengantar Ekonomi Pertanian. CV Andi Offset. Yogyakarta.

Irianto, S, G., 2014. Petunjuk Teknis Pendamping Pengembangan Usaha Agribisnis Perdesaan. Direktorat Jenderal Prasarana dan Saran Pertanian Kementerian Pertanian. Jakarta.

Kamira, D, Noer, M dan Tan F., 2011. Artikel Evaluasi Pelaksanaan Program Pengembangan Usaha Agribisnis Perdesaan (PUAP) di Kota Padang. Program Pasca Sarjana. Universitas Andalas Padang. Padang.Diakses pada http://www.academia.edu/8617623/Eval uasi Dampak Kebijakanpemberdayaan Petani_melalui_Program_BLM-PUAP. Hari jumat 29 Mei 2015.

Manoppo, C., 2007. Pendapatan Usahatani Padi Sawah Varietas Sultan di Desa Kopandakan II Kecamatan Lolayan Kabupaten Bolaang Mongondow. Fakultas Pertanian Universitas Sam Ratulangi. Manado.
Marissa., 2010. Analisis Pendapatan Usahatani Tebu (Studi Kasus PT. PG Rajawali II Unit PG Tersana Baru Babakan Cirebeon Jawa Barat). Program Studi Agribisnis. Fakultas Sains dan Teknologi. Universitas Islam Negri Syarif Hidayahtullah. Jakarta.

Revikasari, A., 2010. Peranan Penyuluh Pertanian Dalam Pengembangan Gabungan Kelompoktani (GAPOKTAN) di Desa Tempuran Kecamatan Paron Kabupaten Ngawi. Program Studi Penyuluhan dan Komunikasi Pertanian.

Salawati, U dan Anita, A, S., 2011. Analisis Pendapatan Penerima Bantuan Langsung Masyarakat-Pengembangan Usaha Agribisnis Perdesaan (BLMPUAP) di Kabupaten Barito Kuala. Program Studi Agribisnis Jurusan FMIPA. Universitas Terbuka. Tangerang. Diakses pada http://faperta unlam.ac.id/web/wpcontent/uploads/do wnloads/2012/03/014-5-Umi-SalawatiAnalisis-Penerima.pdf.Hari Jumat 29 Mei 2015.

Sujarweni, V, W., 2015. SPPS UNTUK PENELITIAN. Pustaka Baru Press. Jl. Wonosari Km 6, Demblaksari RT. 4, Baturetno, Banguntapan, Bantul, Yogyakarta.

Suswono., 2010. Pedoman Umum PUAP. Kementerian Pertanian. Jakarta.

Wibisiono, D, B., 2011. Sikap Petani Terhadap Program Pengembangan Agribisnis Perdesaan (PUAP) di Kota Salatiga. Fakultas Pertanian. Universitas Sebelas Maret Surakarta. Surakarta. Diakses pada http://core.ac.uk/download/pdf/123 50150.pdf. Hari Jumat 29 Mei 2015. 